Research Article

\title{
Experimental Research on Fatigue Behavior of Existing Reinforced Concrete Beams
}

\author{
Guangzhen Qu $\mathbb{D}^{1,},{ }^{1,2}$ Pingming Huang, ${ }^{1}$ Guangli Zhou ${ }^{2}{ }^{2}$ and Sizhong $\mathrm{Lv}^{3}$ \\ ${ }^{1}$ School of Highway, Chang'an University, Xi'an 710064, China \\ ${ }^{2}$ Shandong Transportation Institute, Jinan 250012, China \\ ${ }^{3}$ Shandong Hi-speed Co., Ltd., Jinan 250014, China \\ Correspondence should be addressed to Guangli Zhou; 229993723@qq.com
}

Received 14 July 2020; Revised 31 August 2020; Accepted 29 September 2020; Published 15 October 2020

Academic Editor: Chiara Bedon

Copyright (c) 2020 Guangzhen Qu et al. This is an open access article distributed under the Creative Commons Attribution License, which permits unrestricted use, distribution, and reproduction in any medium, provided the original work is properly cited.

In order to obtain the law of the fatigue damage development of reinforced concrete hollow beams that has been in service for 24 years, its solid hollow beams were removed and transported to the laboratory for loading test. Two beams were selected for static loading to obtain the ultimate flexural bearing capacity, and three beams were, respectively, subjected to constant-amplitude fatigue loading with different load amplitudes. The static and dynamic behaviors of the beams were monitored in the fatigue test. The fatigue failure of the beams showed that the outermost rebar at the butt weld fractured at first, and the crack width at the fracture position of the steel bar was about $0.3 \mathrm{~mm}$, which was largest in all cracks. After a rebar was broken, midspan deflection and flexibility increased by approximately $20 \%$ and $10 \%$, respectively, relative to the initial state. The damage developed rapidly in the following range: (1) the first 10,000 fatigue cycles; (2) after fatigue fracture of the rebar; and in the intermediate stage of fatigue test, the damage development was relatively stable. As the loading amplitude increased, the stiffness degradation and the cumulative damage that occured under the same loading cycle were more significant.

\section{Introduction}

In the last 40 years, most of the bridges in China have been built using reinforced concrete. Due to higher traffic load and increasing traffic volume, the fatigue damage to the bridges increased, which reduced its service life. Fatigue loading was caused by moving wheels and was characterised by a high number of load cycles which may exceed 100 million over the service life of a bridge. Long-term and frequent load action reduced the stiffness of the bridge and showed obvious cumulative damage [1]. More and more scholars were concerned about the fatigue performance and fatigue life of reinforced concrete structures [2-6]. The design code GB 50010 listed the limit values of fatigue design stress amplitude for ordinary steel bars under different fatigue stress ratios [7].

A large number of fatigue test studies on reinforced concrete beams showed that its failure characteristics were generally fatigue fracture of one or part of tensile rebars. The fracture process of rebar can be divided into crack initiation stage, stable crack growth stage and brittle fracture stage [8-11]. Chang et al. studied the relationship between crack development, midspan deflection, steel strain, and fatigue load through the fatigue performance test of 11 reinforced concrete specimens and finally obtained the S-N curve of the reinforced concrete beams [12]. Li et al. analyzed and studied the fatigue performance of flexural members through static load and constant-amplitude fatigue tests on high-strength concrete simply supported beams equipped with new grade III steel and gave calculations method for the compression zone concrete stress and longitudinal tensile steel bar stress and design value of fatigue strength of steel bars [13]. Wang et al. conducted fatigue tests of reinforced concrete beams in air, fresh water, and salt water environments and studied the deformation development process and fatigue life of the beams in three environments under repeated loads [14]. Yang et al. studied the fatigue behavior decay law of reinforced concrete beams through 150-time 
water freeze-thaw and salt freeze-thaw cycles [15]. Yu et al. conducted fatigue tests on 12 pieces of $1: 6$ scale model beams to study the fatigue failure form, amplitude, stiffness, steel strain, and concrete strain of heavy-haul railway bridge with the number of repeated loads [16]. Li et al. made three rectangular section beams and three T-shaped section beams and studied the influence of reinforcement ratio, section shape, and reinforcement stress on the fatigue performance of reinforced concrete members [17]. Aidoo et al. carried out fatigue tests on eight RC T-beams strengthened with and without CFRPs (carbon fiber-reinforced plastics) and concluded that the fatigue life of a RC beam could be increased using FRPs and that the fatigue behavior was controlled by the fatigue behavior of the reinforcing steel [18].

However, most fatigue loading tests were based on reduced-scale model beams and few tests on full-scale members, and the dynamic characteristics of the component in the fatigue test have not been concerned during the fatigue test.

The aims of this paper are as follows: (1) to identify an interest in enhancing knowledge of the fatigue behaviour of concrete bridges; (2) to understand the impact of different overload levels on concrete bridges; (3) to describe the fatigue of reinforced concrete. Based on the above analysis, in this study, four hollow beams in service for 24 years were taken as the test objects, and the static and constant-amplitude fatigue loading tests were carried out in the laboratory. Beam failure mode, deflection, strain of concrete and rebars, and vibration mode changes were recorded during loading, and the development of fatigue damage was summarized.

\section{Test Design}

2.1. Test Specimen. The testing beams were originally located on Jinan-Qingdao Expressway of Shandong Province, which was completed in 1993. At present, the expressway needed to be expanded to accommodate more traffic. In this process, a 24-year $8 \mathrm{~m}$-span RC hollow beam was dismantled from the bridge and transported back to the laboratory for fatigue test to evaluate its residual life. The demolition and storage of the test beams are shown in Figure 1.

The original design height of the test beam was $40 \mathrm{~cm}$, and there was a $17 \mathrm{~cm}$ thick concrete leveling layer. The designed strength grade for the concrete was C25. The bottom longitudinal rebars of the beam were $25 \mathrm{~mm}$ in diameter with spiral ribbing, and the stirrups and top construction rebars used plain round steel with $8 \mathrm{~mm}$ diameter. The two outermost longitudinal steel bars were welded to the diagonal steel bars. The dimensions of the test specimens are shown in Figure 2, and the measured material parameters of concrete and rebar are shown in Tables 1 and 2 , respectively.

2.2. Test Scheme. The beams were simply supported and tested under a four-point bending configuration. The clear span and shear span were 7.62 and $2.81 \mathrm{~m}$, respectively. Displacement gauges were installed at the middle span, at the one-fourth span position, and at both ends of the beam. The concrete strain gauges were placed in the midspan web surface of the beam, and the bottom concrete at the reinforcement location was cut out to place the rebar strain gauges. The appearance and propagation of the cracks were observed visually, and a digital crack-width viewer was used to measure the crack widths. The vibration sensors were arranged on the top plate of the hollow beam to collect the modal information, as shown in Figure 3.

The JD1 test beam was used for static load test to determine ultimate load needed in the fatigue experiment, and the JP1 to JP3 beams were used for fatigue tests under different load levels $[9,19]$. Specific experimental conditions are shown in Table 3.

\subsection{Test Device and Loading Method}

2.3.1. Test Device. The test was carried out using MTS electrohydraulic servo loading equipment, which can not only realize the multichannel independent test but also compile the complex fatigue load block spectrum, display, and monitor the graph of the test results in real time. It had the functions of system internal lock protection and automatic damage detection too. The MTS control system and hydraulic oil source are shown in Figure 4. The static and fatigue tests were all conducted using the fatigue testing system, and loading device for experiments is shown Figure 5.

\subsubsection{Loading Method}

(1) Static load test. The ultimate load $P_{u}$ can be obtained by monotonic loading test. The beams should first be preloaded before the formal test. The monotonic load test was carried out through graded loading, with a load increment of $25 \mathrm{kN}$ and encryption in the later stage.

(2) Fatigue load test. The beams were preloaded to check that the test instrument was working properly, and then the initial state of test beam was collected through static load to the upper limit of fatigue. Then, sine wave loading was used in fatigue test with the loading frequency of $3 \mathrm{~Hz}$. When a certain number of cycles were reached, the static load test was carried out to the upper limit of fatigue. After static loading, the fatigue loading test was continued until the component was damaged. The loading program is shown in Figure 6.

\section{Static Load Test}

The static load test was carried out on the JD1 beam. Before loading, there were several original cracks in the constant moment region of the beam, and the original crack height was about $10 \mathrm{~cm}$ and the maximum width was $0.1 \mathrm{~mm}$. As the load increased, the number of cracks in the test beam increased, and the crack width and height increased. Before the longitudinal tensile rebar entered the yield phase, the components showed 


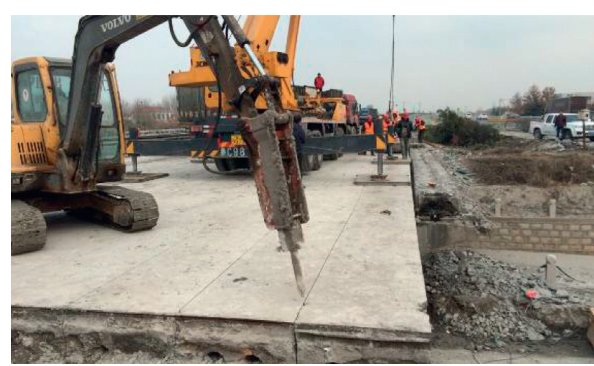

(a)

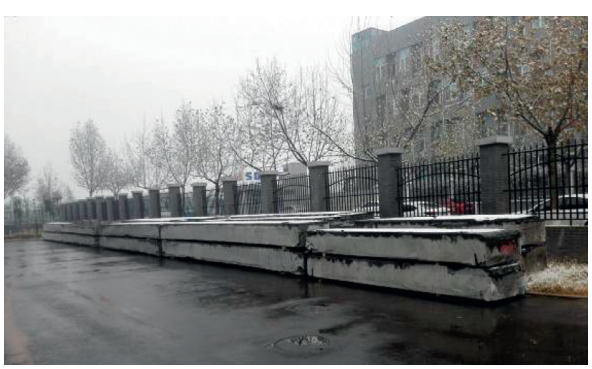

(b)

Figure 1: In situ construction: (a) demolition; (b) storage.

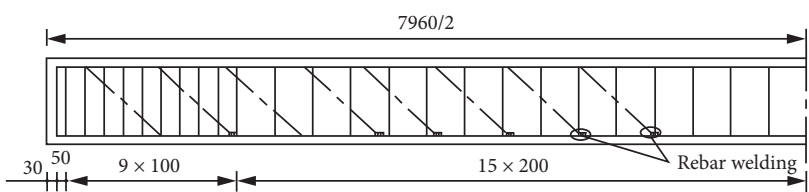

(a)

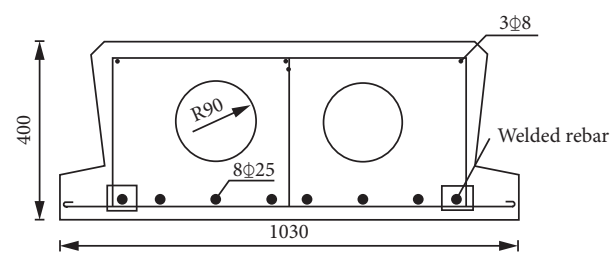

(b)

FIGURE 2: Dimensions and reinforcement of tested beams: (a) longitudinal section reinforcement (half span) (unit: $\mathrm{cm}$ ); (b) cross section (unit: $\mathrm{mm}$ ).

TABLE 1: Material properties of concrete.

\begin{tabular}{lcc}
\hline Compressive strength $(\mathrm{MPa})$ & Elastic modulus $(\mathrm{GPa})$ & Density $\left(\mathrm{kg} / \mathrm{m}^{3}\right)$ \\
\hline 44.9 & 32.5 & 2450 \\
\hline
\end{tabular}

TABLE 2: Material properties of rebar.

\begin{tabular}{lccc}
\hline & Yield strength $(\mathrm{MPa})$ & Ultimate strength $(\mathrm{MPa})$ & Elastic modulus $(\mathrm{GPa})$ \\
\hline$\varphi 25$ & 381 & 532 & 204 \\
$\varphi 8$ & 277 & 403 & 213 \\
\hline
\end{tabular}

good elasticity and the load-deflection curve showed a linear relation; the width of the crack grew relatively slowly and remained within $0.5 \mathrm{~mm}$, and the crack was essentially closed after unloading. With loading to approximately $0.9 \mathrm{Pu}$, the longitudinal tensile rebar entered the yield phase, and the deflection reached approximately $1 / 400^{\text {th }}$ of the calculated span. At this phase, the load increased gradually, whereas the midspan deflection increased rapidly. With the continuous increase of load, the number of cracks no longer increased, the crack distribution was more uniform, and the neutral axis continued moving upwards until the strain of rebar exceeded the limit strain of 0.01 [20]. Ultimately, the ultimate load was $502 \mathrm{kN}$. The failure shape and crack distribution of JD1 beam are shown in Figure 7. The load-midspan deflection curve is shown in Figure 8, and the load-rebar strain curve is shown in Figure 9.

\section{Fatigue Load Test}

4.1. Observed Behavior. Under cyclic loading, there was no obvious sign before the fatigue failure of the test beam. With the continuous fatigue loading, an outermost longitudinal tensile steel bar near the midspan side suddenly broke at the welding position (Figure 10). The first failure of the steel bar at the welding location was due to the existence of welding residual stress, and the fatigue fracture of the beams first occurred at the position of stress concentration [21]. After the longitudinal tensile steel bar 


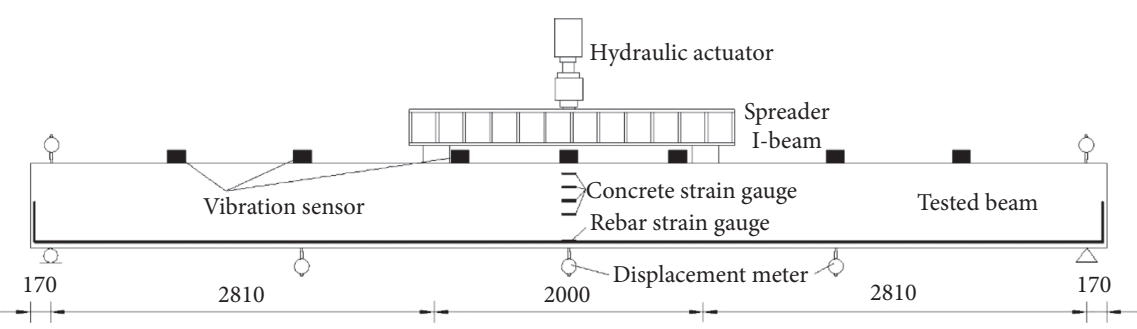

FIgURE 3: Test scheme and layout of measuring points (unit: $\mathrm{mm}$ ).

TABLE 3: Test conditions.

\begin{tabular}{|c|c|c|c|c|}
\hline \multirow{2}{*}{$\begin{array}{l}\text { Specimen number } \\
\text { JD1 }\end{array}$} & \multicolumn{3}{|c|}{ Loading system } & \multirow{2}{*}{$\begin{array}{l}\text { Loading instructions } \\
\text { Get the ultimate load, } \mathrm{Pu}\end{array}$} \\
\hline & & Static loading test & & \\
\hline JP1 & $\begin{array}{c}\text { Fatigue upper limit }\left(P_{\max }\right) \\
0.5 \mathrm{Pu}\end{array}$ & $\begin{array}{c}\text { Fatigue lower limit }\left(P_{\min }\right) \\
0.1 \mathrm{Pu}\end{array}$ & $\begin{array}{c}\text { Amplitude }(\Delta P) \\
0.4 \mathrm{Pu}\end{array}$ & Fatigue load amplitude \\
\hline JP2 & $0.6 \mathrm{Pu}$ & $0.1 \mathrm{Pu}$ & $0.5 \mathrm{Pu}$ & Fatigue loading to failure \\
\hline JP3 & $0.7 \mathrm{Pu}$ & $0.1 \mathrm{Pu}$ & $0.6 \mathrm{Pu}$ & \\
\hline
\end{tabular}

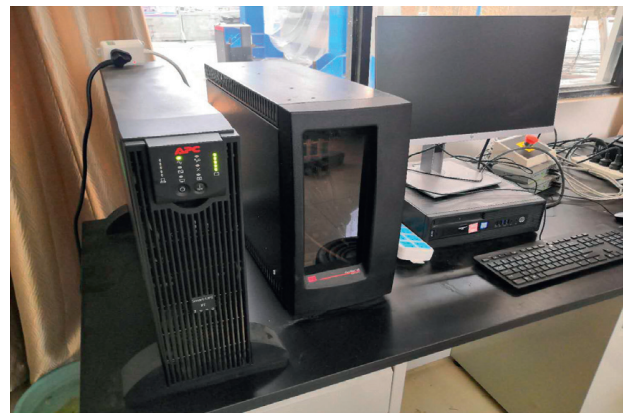

(a)

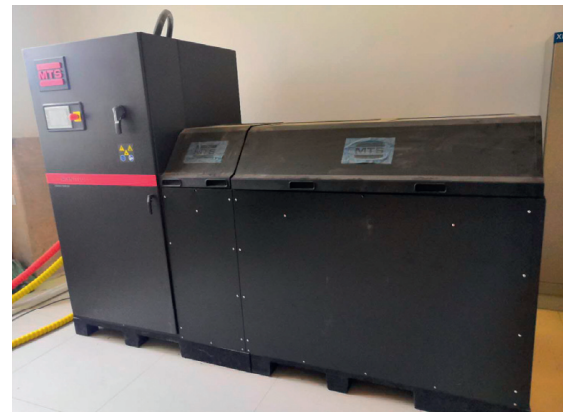

(b)

Figure 4: The MTS: (a) control system; (b) hydraulic oil source.

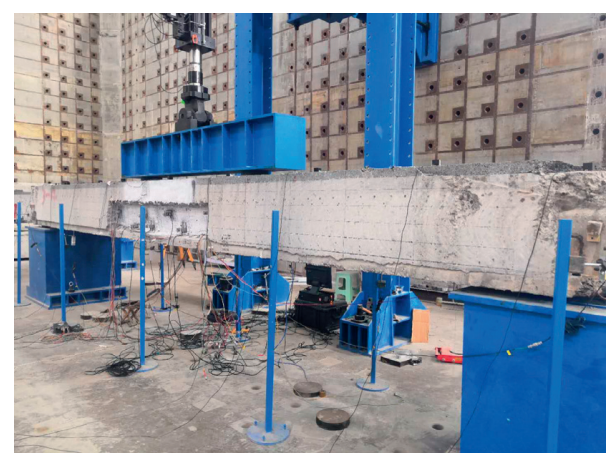

FIGURE 5: Loading device for experiments.

was broken, the beam did not collapse and still continued to bear the fatigue load. The concrete in the compression zone was not crushed, and there was no obvious abnormality.

The cracks in the constant moment region of the beam gradually developed along the original cracks slowly; when the outermost steel bar suddenly broke, the crack width increased significantly near the fracture, and the vertical crack width at the web after the steel bar broke was about
$0.3 \mathrm{~mm}$, and the width of some cracks at other locations had decreased. The fatigue failure shape and crack distribution of JP2 beam are shown in Figure 11.

4.2. Deflection. The load-midspan deflection curves of JP1 JP3 beams in different cycle times are shown in Figure 12. As shown in the figure, the midspan deflection changed linearly with the increase of load before and after 


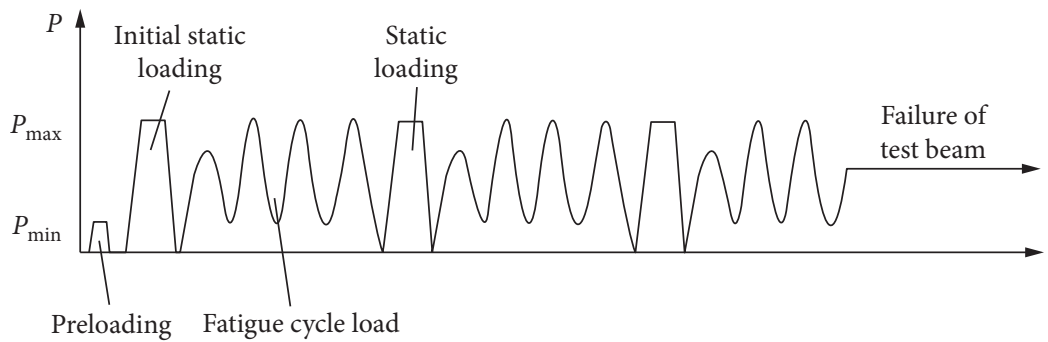

FIGURE 6: Fatigue loading program.

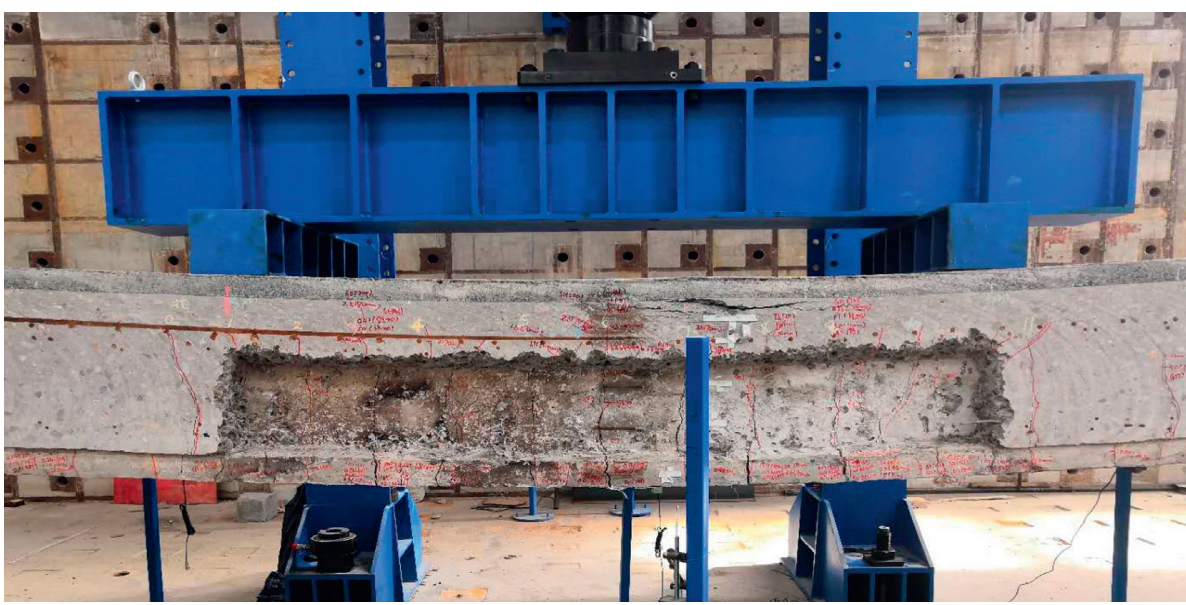

(a)

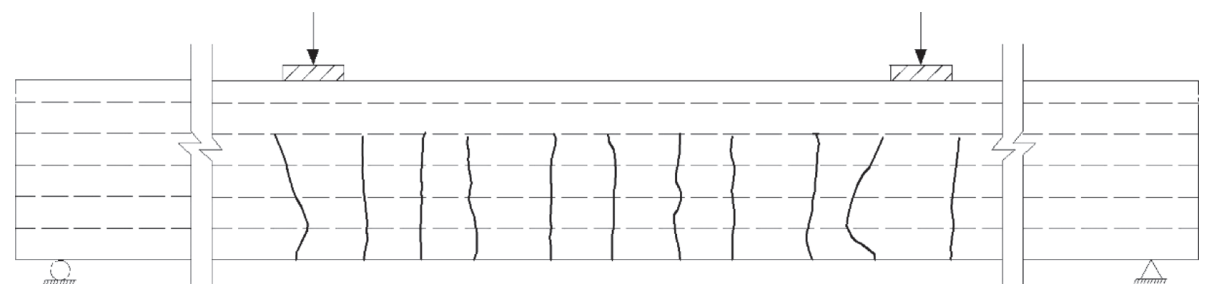

(b)

Figure 7: Failure shape and crack distribution of test beam: (a) failure shape; (b) crack distribution.

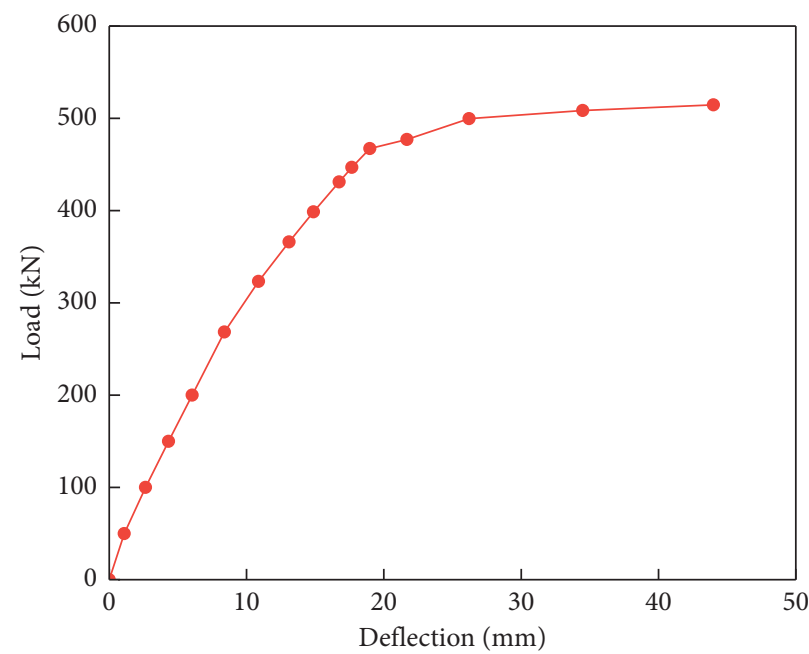

FIgURE 8: Load-midspan deflection curve. 


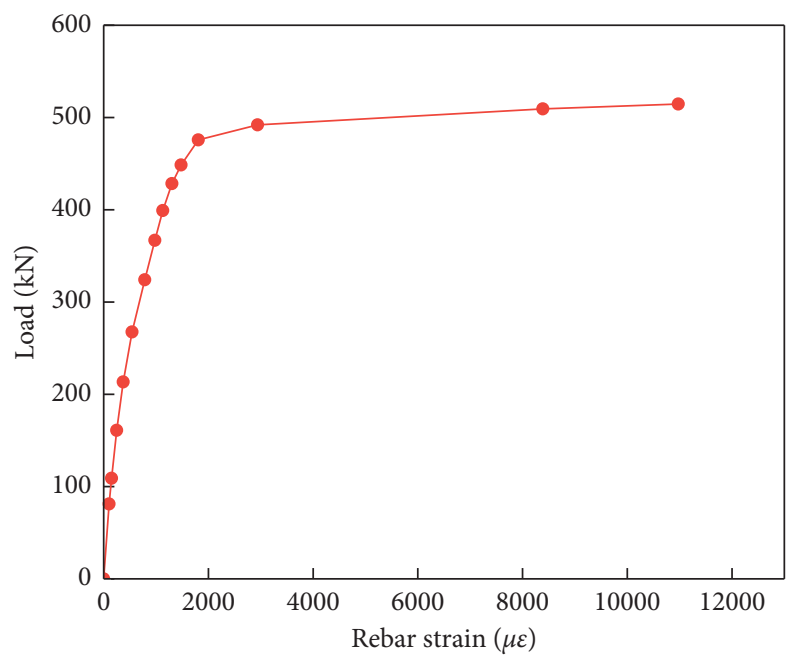

FIGURE 9: Load-rebar strain curve.

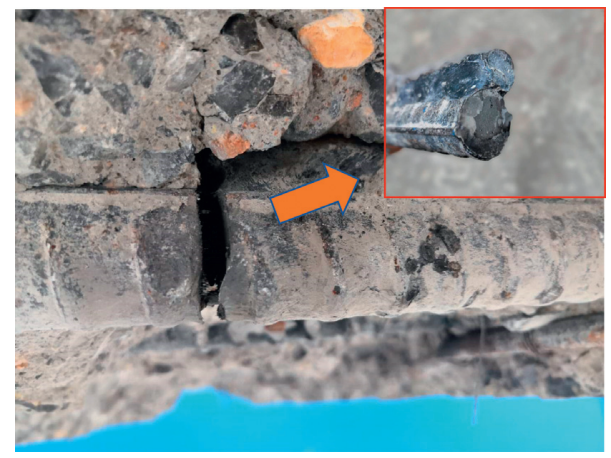

Figure 10: Fatigue fracture of steel bar.

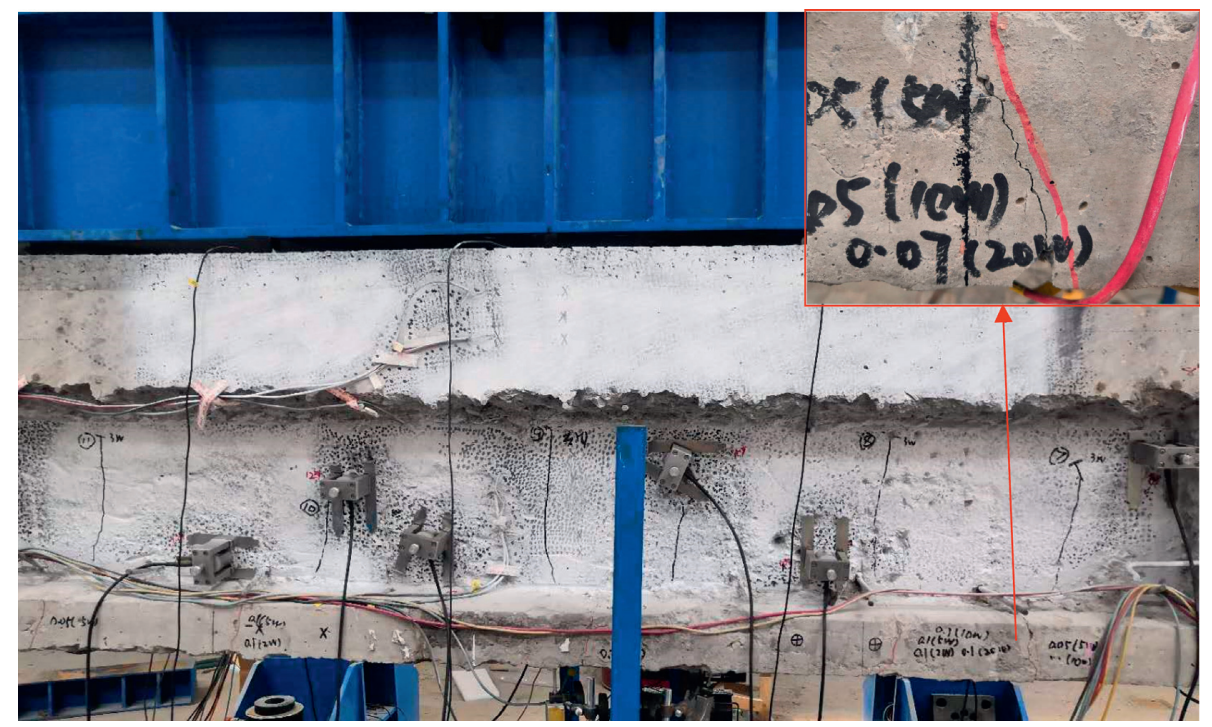

(a)

Figure 11: Continued. 


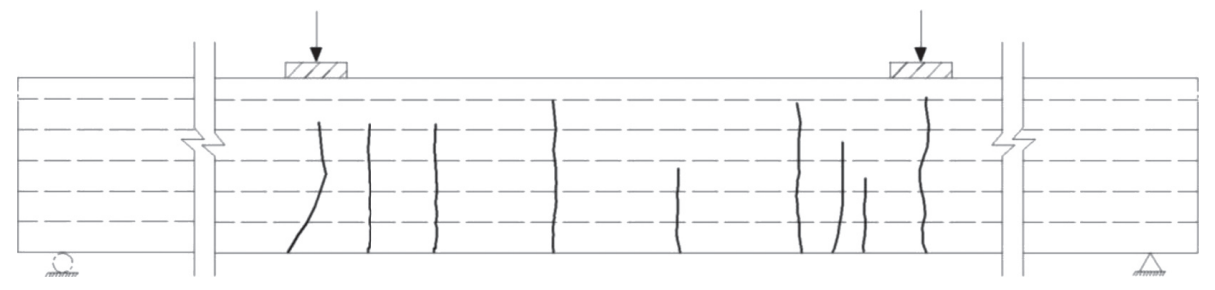

(b)

FIGURE 11: Fatigue failure shape and crack distribution of JP2 beam: (a) failure shape; (b) crack distribution.

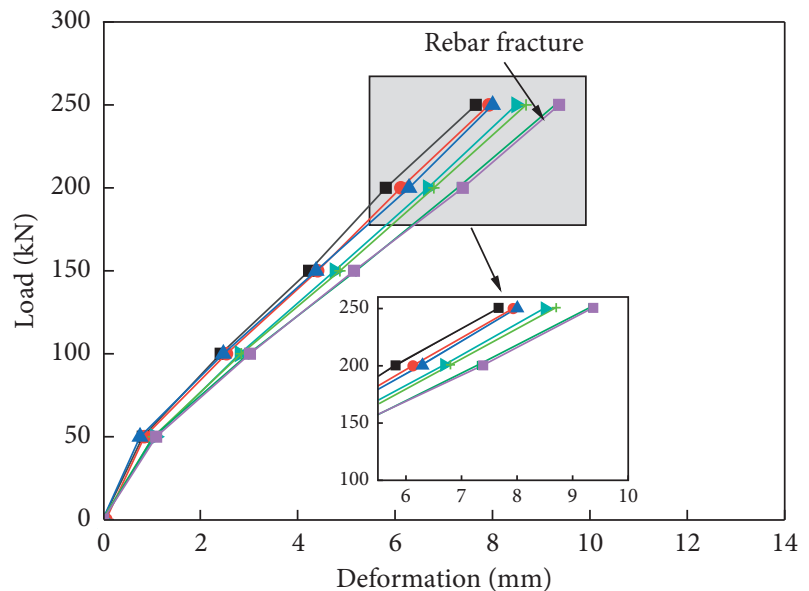

Number of cycles $\left(10^{4}\right)$

$\rightarrow 0$

$\rightarrow 1$

$-10$

$\rightarrow-50$

$\longrightarrow 100$

$\rightarrow-158$

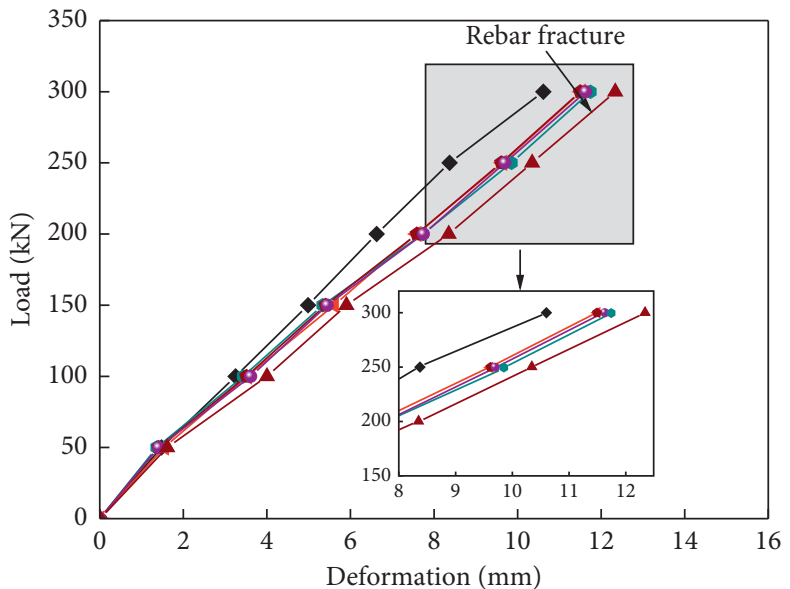

Number of cycles $\left(10^{4}\right)$

$-0$

$-4-1$

$-30$

(a)

(b)

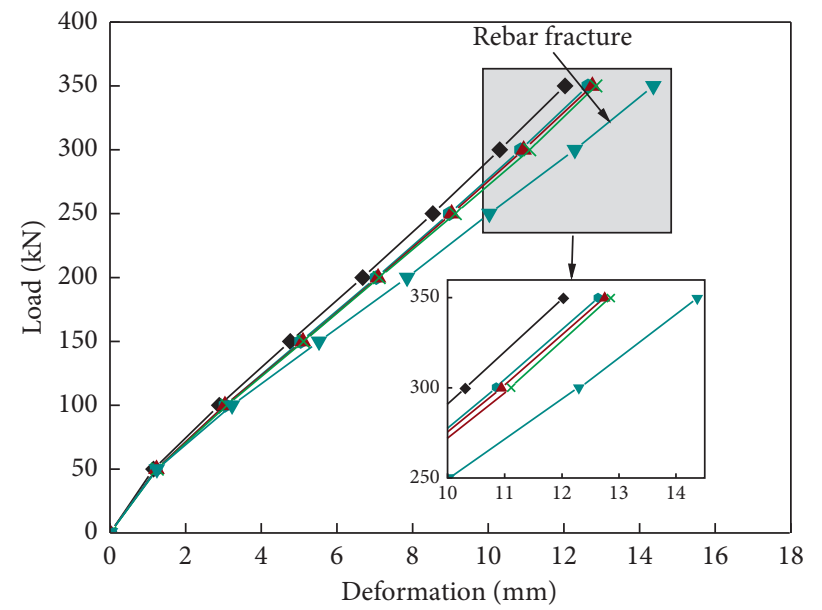

Number of cycles $\left(10^{4}\right)$

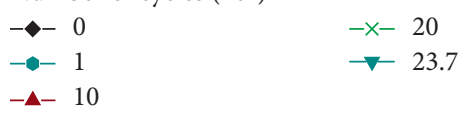

(c)

Figure 12: Load-midspan deflection in (a) JP1; (b) JP2; and (c) JP3. 


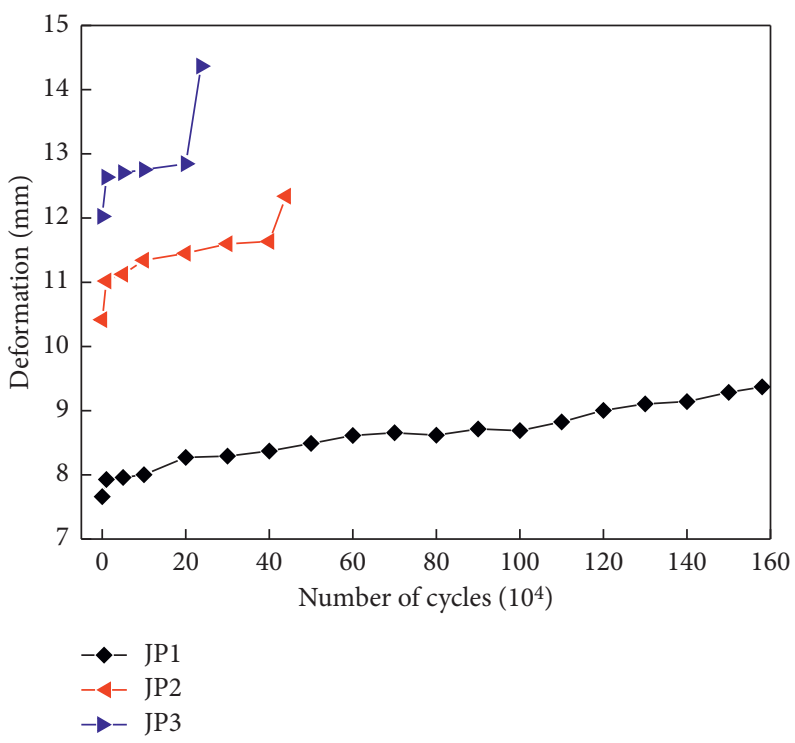

Figure 13: Relation curve for deflection and fatigue cycles.

rebar fracture. Figure 13 shows that the midspan deflection under the fatigue upper limit varied with the number of cycles. The midspan deflection of the test beams increased gradually with the increase of the number of cycles. The midspan deflection changed more obviously in the following range: (1) the first 10,000 fatigue cycles; (2) after fatigue fracture of the rebar.

After the rebar fracture, the midspan deflection of JP1, JP2, and JP3 beams increased by 1.63, 1.92, and $2.34 \mathrm{~mm}$ relative to the initial stage, and the increase rates were $21.2 \%$, $18.4 \%$, and $19.5 \%$ respectively, which indicated that the stiffness of the test beams were greatly reduced.

4.3. Strain of Material. In the process of cyclic loading, the average strain on the rebar and concrete in a section of the beam was taken as the representative of the corresponding strain in that section. The load-midspan rebar strain curves of JP1 JP3 beams in different cycle times are shown in Figure 14. It can be seen from the figure, the midspan longitudinal tensile rebar strain changed linearly with the increase of load before and after rebar fracture. Figure 15 shows that the midspan longitudinal tensile rebar strain under the fatigue upper limit varied with the number of cycles. The midspan rebar strain changed more obviously in the following range: (1) the first 10,000 fatigue cycles; (2) after fatigue fracture of the rebar. After the rebar fracture, the midspan longitudinal tensile rebar strain of JP1, JP2, and JP3 beams decreased by $40 \mu \varepsilon, 55 \mu \varepsilon$, and $124 \mu \varepsilon$ relative to one cycle before rebar fracture, and the reduction rates were $6.9 \%, 6.7 \%$, and $12.3 \%$, respectively.

The load-compressive strain of top edge concrete of JP1 JP3 beams in different cycle times are shown in Figure 16. During the initial loading stage, when the number of cycles was below 10,000, the strain of concrete grew rapidly. As the cracks developed, it gradually entered the stable stage. Until the rebar fracture, the strain of concrete changed very little. The strain of the concrete at the top edge compression zone of the beam and the longitudinal tensile rebar strain did not reach yield strain throughout the loading process. The mechanical behavior of the concrete beams under cyclic loading was largely determined by the presence of tensile rebars.

4.4. $S \sim N$ Curve. In the fatigue test of RC beam, the tensile steel bar stress amplitude can be calculated according to the following formula:

$$
\begin{gathered}
\Delta \sigma_{s}^{f}=\sigma_{s, \text { max }}^{f}-\sigma_{s, \text { min }}^{f}, \\
\sigma_{s, \text { max }}^{f}=\alpha_{E}^{f} \frac{M_{\text {max }}^{f}\left(h_{0}-x_{0}\right)}{I_{0}^{f}}, \\
\sigma_{s, \text { min }}^{f}=\alpha_{E}^{f} \frac{M_{\text {min }}^{f}\left(h_{0}-x_{0}\right)}{I_{0}^{f}},
\end{gathered}
$$

where $M_{\max }^{f}$ and $M_{\min }^{f}$ are the bending moments produced by the upper and lower fatigue loads respectively; $\alpha_{E}^{f}$ is the ratio of the elastic modulus of steel bar to that of concrete; $x_{0}$ is the height of compression zone of the cross section; $h_{0}$ is the effective height of the cross section; $I_{0}^{f}$ is the moment of inertia of the converted section.

The theoretical tensile steel bar stress amplitude can be calculated by the formula above. The test and calculated values are shown in Table 4.

The failure mode of the test was mainly the fatigue fracture of steel bar, and the $\mathrm{S} \sim \mathrm{N}$ curve with stress amplitude as parameter was usually used to deal with the fatigue life of steel bar. The standard formula is as follows [22, 23]:

$$
\lg (N)=A-B \lg \left(\Delta \sigma_{s}^{f}\right),
$$



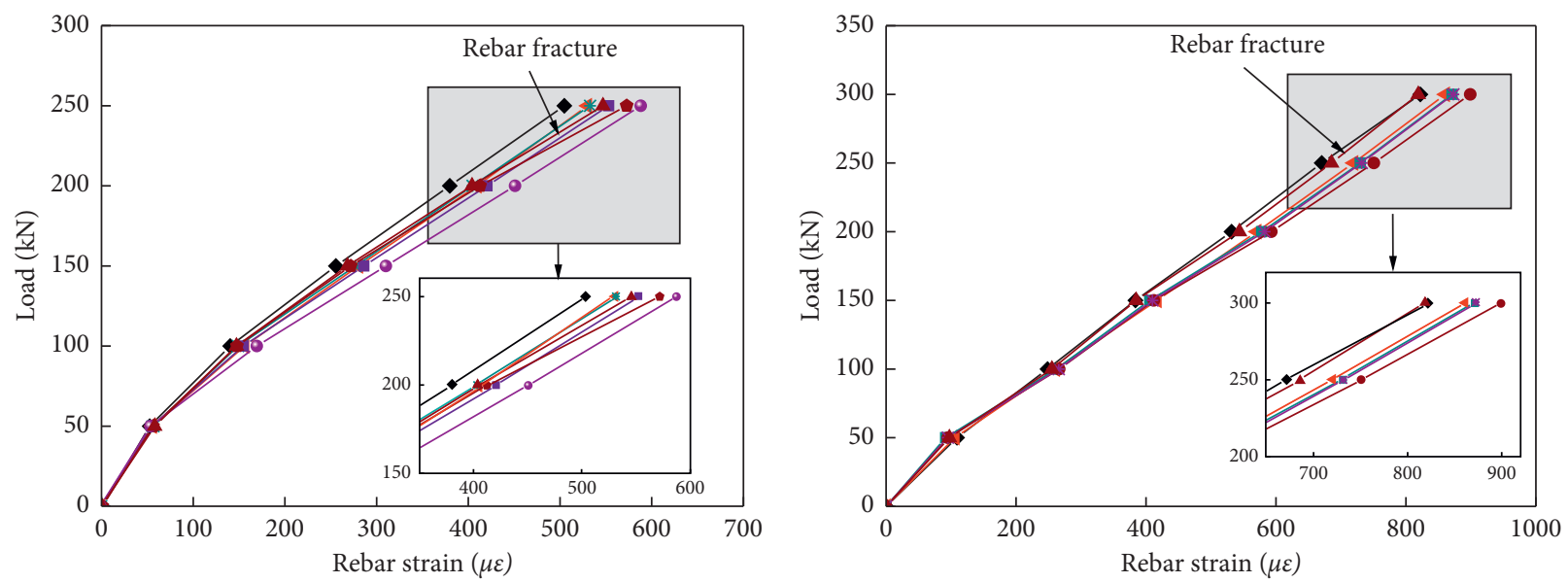

Number of cycles $\left(10^{4}\right)$

$\begin{array}{ll}-\triangleleft \\ -\triangleleft & 0\end{array}$

$-100$

Number of cycles $\left(10^{4}\right)$

$-4-1$

$-150$

$-\bullet 0$

$-\bullet-30$

$-4-1$

-*- 40

$-\square-50$

(a)

(b)

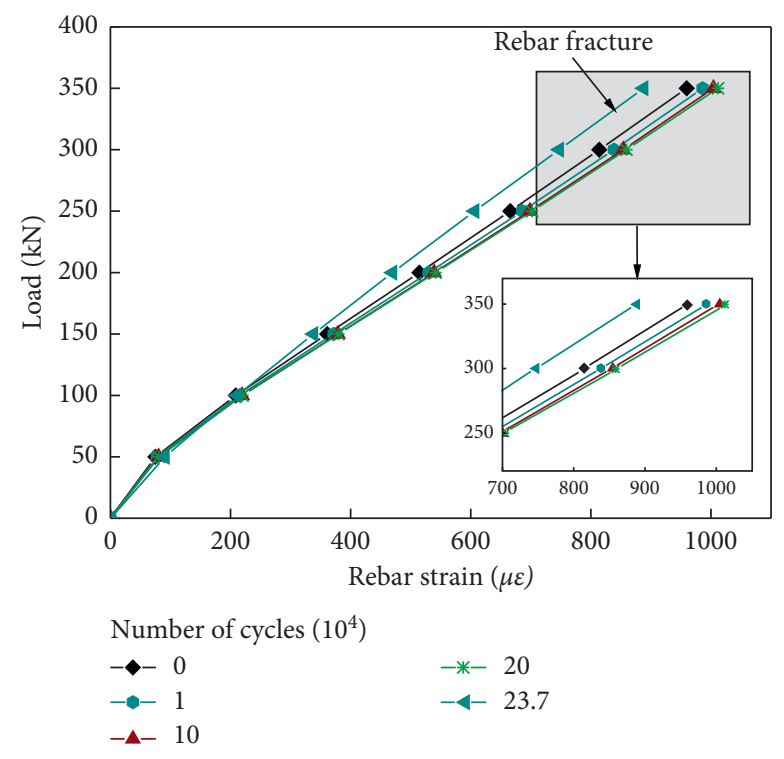

(c)

Figure 14: Load-midspan rebar strain in (a) JP1; (b) JP2; and (c) JP3.

where $\mathrm{A}$ and $\mathrm{B}$ are constants related to the type and connection form of steel bars; $N$ is the number of fatigue failures; and $\Delta \sigma$ is the steel bar stress amplitude.

Table 5 shows the information summary of the test beams. The relationship between stress amplitude of rebars and the fatigue life of the beams was established by the using double logarithmic curve. The $\mathrm{S} \sim \mathrm{N}$ curve was obtained by linear regression simulation, as shown in Figure 17. The linear regression curve equation was as follow:

$$
\lg N=11.41-2.6633 \lg \Delta \sigma_{s}^{f} .
$$

The correlation coefficient R2 is 0.997 . It can be seen that each point agrees well with the regression equation, and the obtained curve has high reliability.

\section{Dynamic Performance in Fatigue Test}

In order to further analyze the change law of the dynamic performance of the hollow slab from the initial state to the rebar fracture, the JP2 beam was subjected to modal testing under environmental excitation after a certain fatigue loading cyclic. Figure 18(a) shows the changes of the first two 


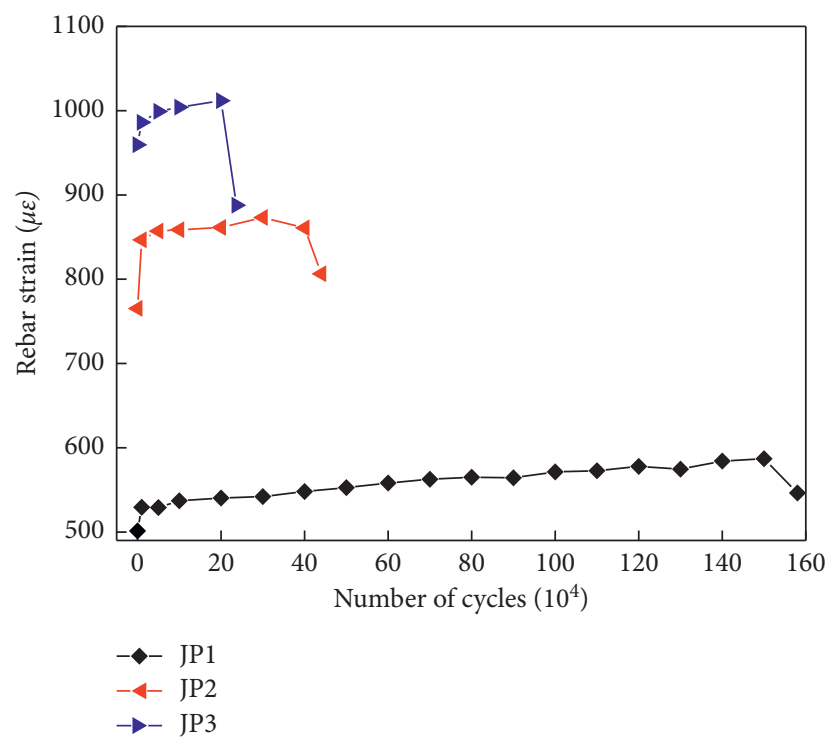

FIGURE 15: Relation curve for longitudinal tensile rebar and fatigue cycles.
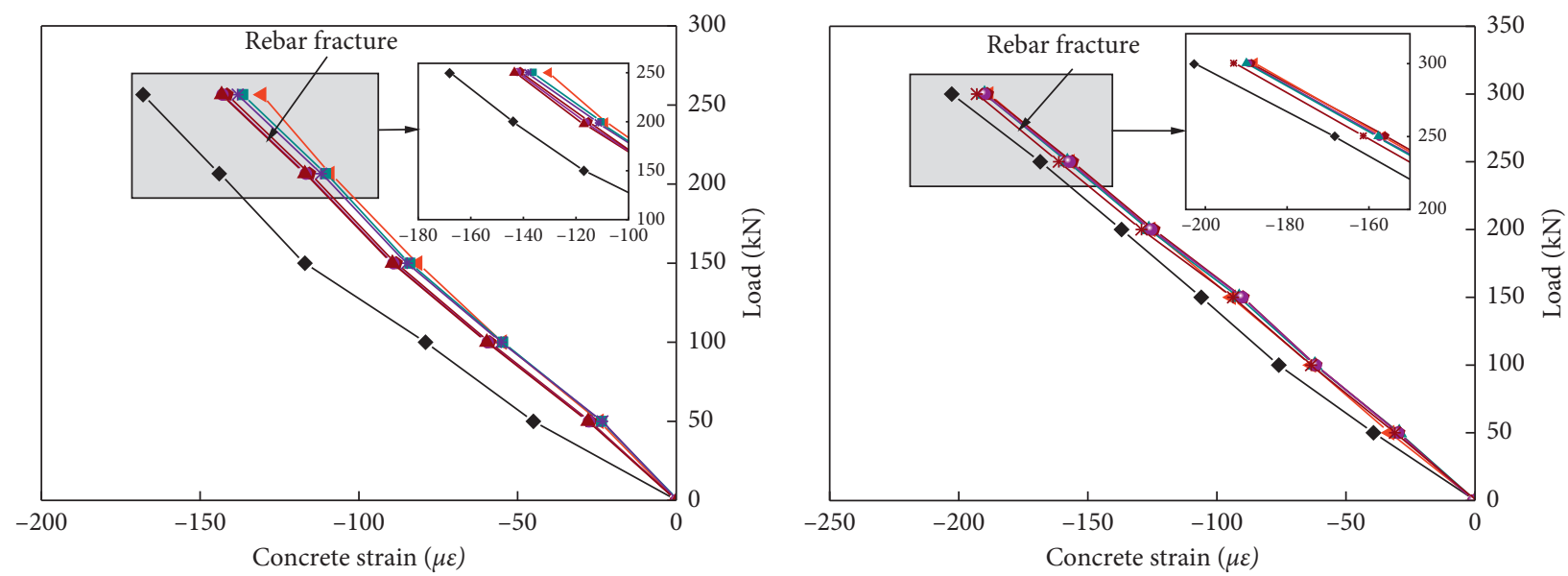

Number of cycles $\left(10^{4}\right)$

$\begin{array}{ll}-\bullet 0 & -\bullet 100 \\ -\triangleleft-1 & -\bullet 150 \\ --10 & -\boldsymbol{-}-158 \\ -*-50 & \end{array}$

Number of cycles $\left(10^{4}\right)$

$\begin{array}{ll}-\bullet-0 & -\bullet 30 \\ -\triangleleft-1 & -\bullet 40 \\ -\boldsymbol{-}-10 & -*-44\end{array}$

(a)

(b)

FIgURe 16: Continued. 


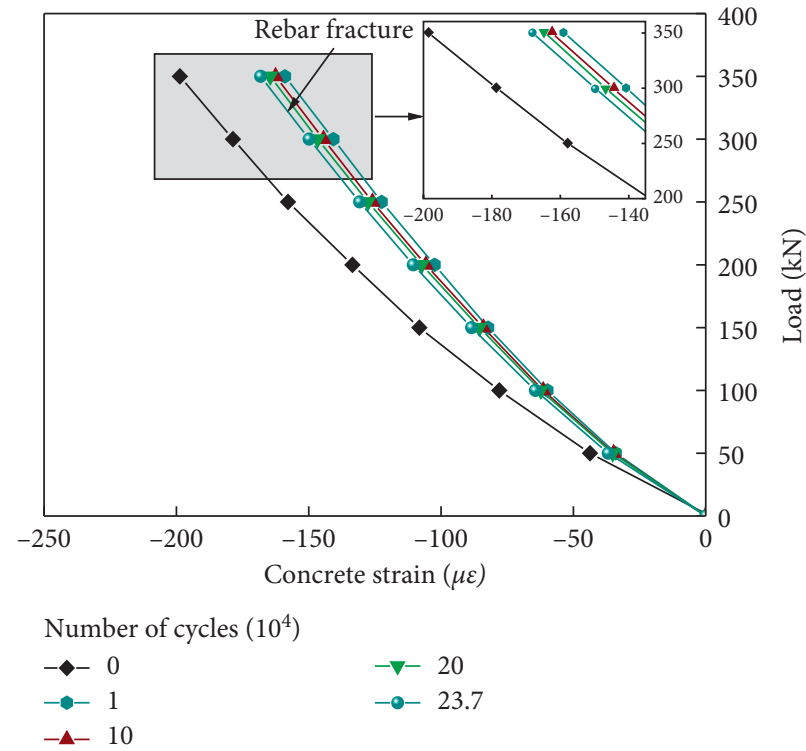

(c)

FIGURE 16: Load-compressive strain on concrete in (a) JP1; (b) JP2; and (c) JP3.

TABLE 4: Tensile stress of rebar at different loads.

\begin{tabular}{lcccc}
\hline Loads $(\mathrm{kN})$ & 50 & 251 & 301 & 351 \\
\hline Calculated values $(\mathrm{MPa})$ & 12.1 & 181.5 & 217.6 & 253.8 \\
Test values $(\mathrm{MPa})$ & 18.1 & 107.9 & 166.8 & 199.3 \\
\hline
\end{tabular}

TABLE 5: Information data sheet of test beams.

\begin{tabular}{lccccc}
\hline Specimen number & $P_{\min }(\mathrm{kN})$ & $P_{\max }(\mathrm{kN})$ & Fatigue stress ratio & Stress amplitude of tensile rebar $\Delta \sigma_{s}^{f}(\mathrm{MPa})$ & Fatigue life $\left(10^{4}\right.$ cycles $)$ \\
\hline JP1 & 50 & 251 & 0.199 & 89.8 & 158 \\
JP2 & 50 & 301 & 0.166 & 148.7 & 44 \\
JP3 & 50 & 351 & 0.142 & 181.2 & 23.7 \\
\hline
\end{tabular}

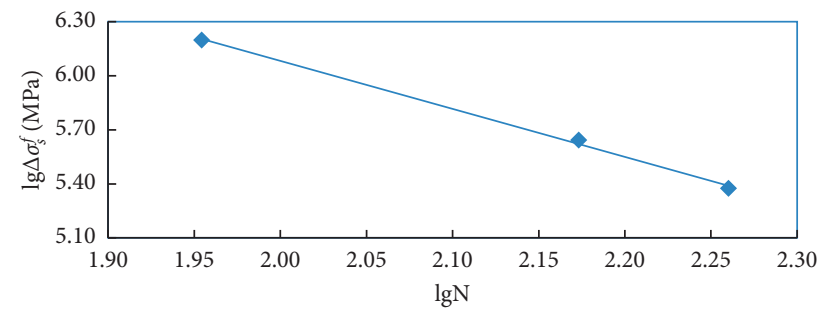

FIgURE 17: S N curve.

order natural vibration frequencies of JP2 beam under different cycles. It can be seen from the figure that the natural vibration frequencies were decreasing continuously. After the fracture of longitudinal tensile reinforcement, the firstand second-order frequencies were reduced by $3.5 \%$ and $2.5 \%$, respectively, compared with those of the initial state.

Pandey and Biswas first proposed the use of the curvature mode method to identify damage [24]. Li et al. proposed that the curvature mode $\phi_{k}^{\prime \prime}$ can be obtained by differential calculation of displacement mode [25]:

$$
\phi_{k}^{\prime \prime}=\frac{\varphi_{k+1}-2 \varphi_{k}+\varphi_{k-1}}{\left(l_{k-1} l_{k}\right)}, \quad k=1,2 \ldots
$$

where $\varphi_{k}$ is the vibration mode of the $k$-th measuring point and $l_{k} l_{k-1}$ is the distance between two adjacent measuring pointskand $k-1$.

In addition, higher-order curvature modes were more sensitive to damage, and second-order curvature modes were obtained by differential calculation of second-order displacement modes of JP2 beam, as shown in Figure 18(b). 


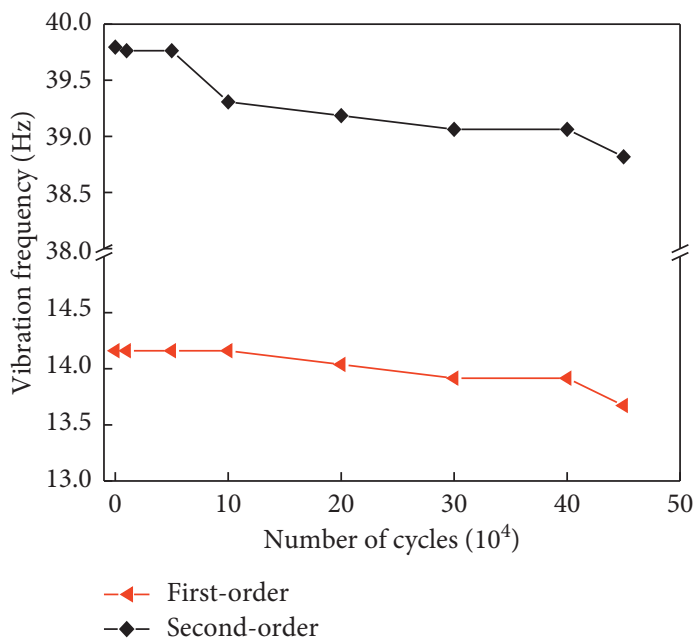

(a)

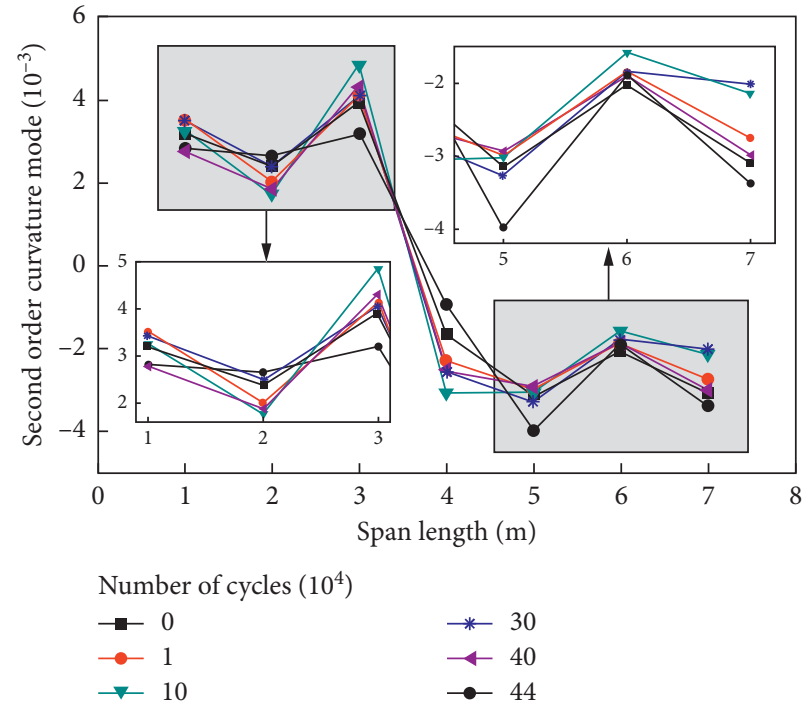

(b)

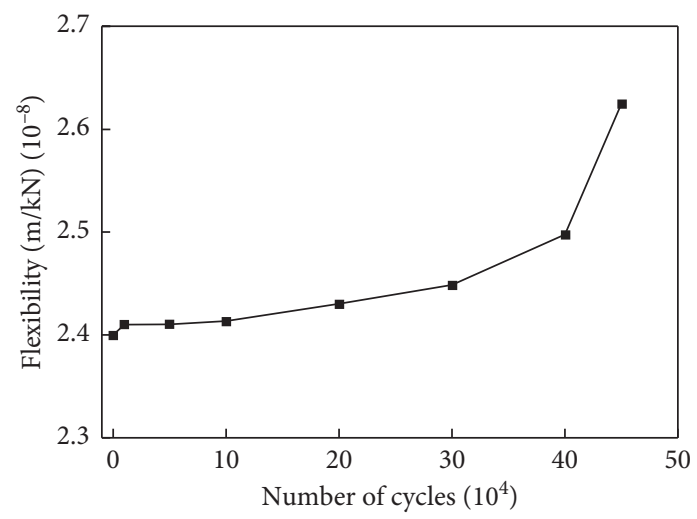

(c)

Figure 18: Dynamic performance of JP2 beam: (a) first two order natural frequencies; (b) second-order curvature mode; (c) midspan flexibility.

It can be seen from the figure that after the longitudinal tensile steel bar broke, the curvature near the midspan of the test beam changed greatly, which was a large damage that occurred near the midspan. The compliance matrix based on frequency and mode can achieve quantitative analysis of damage, and its formula is as follows [26]:

$$
D=\sum_{i=1}^{M} \frac{\varphi_{m i} \varphi_{m i}^{T}}{\omega_{i}^{2}}, \quad i=1,2 \ldots
$$

where $\omega_{i}$ is the $i$-th measured circle frequency and $\varphi_{m i}$ is the $i$-th mass normalized mode.

The flexibility change of the JP2 beam in the middle of the span after the fatigue load cycle is shown in Figure 18(c). It can be seen from the figure that the midspan flexibility increased steadily as the number of cyclic loading increased, but after the longitudinal tensile rebar broke, the midspan flexibility increased significantly, which was $10 \%$ higher than that before fatigue cyclic loading.

\section{Conclusions}

A series of experiments were carried out to investigate the mechanical behavior of reinforced concrete beams in service under fatigue cyclic loading; beam failure mode, deflection, strain of concrete and rebars, and vibration mode changes were recorded during loading; also the development of fatigue damage was summarized. Based on the test results, the main conclusions were as follows:

(1) The fatigue failure of the hollow beam indicated that the outermost rebar at the butt weld fractured firstly, and the crack width at the fracture position of the steel bar was about $0.3 \mathrm{~mm}$, which was largest of all cracks.

(2) After the rebar fracture, the midspan deflection increase rate of three beams was $18.4 \%-21.2 \%$ relative to the initial state, and the tensile reinforcement in the middle of the span decreased suddenly, while the concrete strain in the top compression zone remained basically unchanged. 
(3) The damage developed rapidly in the following range: (1) the first 10,000 fatigue cycles; (2) after fatigue fracture of the rebar; and the damage development was relatively stable in the intermediate stage of the fatigue test.

(4) After the rebar fracture, the first- and second-order frequencies were reduced by $3.5 \%$ and $2.5 \%$, respectively, and the midspan flexibility was increased $10 \%$ compared with that of the initial state.

\section{Data Availability}

The data used to support the findings of this study are available from the corresponding author upon request.

\section{Conflicts of Interest}

The authors declare no conflicts of interest.

\section{Acknowledgments}

This research was funded by Transportation Science and Technology Innovation Project of Shandong Province (Grant no. 2016B49). The authors greatly appreciate the support.

\section{References}

[1] J. Q. Zhang, P. F. Li, Y. Mao, and Z. H. Dong, "The mechanical properties of reinforced concrete plate-girders when placed under repeated simulated vehicle loads," Materials, vol. 12, no. 11, pp. 1-14, 2019.

[2] M. Do, O. Chaallal, and P. Aitcin, "Fatigue behavior of highperformance concrete," Journal of Materials in Civil Engineering, vol. 5, no. 4, pp. 96-111, 1993.

[3] J. O. Holmen, "Fatigue of concrete by constant and variable amplitude loading," ACI Special Publication, vol. 75, pp. 71110, 1982.

[4] H. J. Chen, Y. B. Peng, and Q. S. Zhang, "Research on fatigue behavior of concrete beams reinforced by cold-roiled deformed steel bar," China Journal of Highway and Transport, vol. 19, no. 1, pp. 23-27, 2006.

[5] M. Schläfli and E. Brühwiler, "Fatigue of existing reinforced concrete bridge deck slabs," Engineering Structures, vol. 20, no. 11, pp. 991-998, 1998.

[6] C. S. Wang, J. Zhou, Q. Y. Wu et al., "Fatigue life and service safety assessment for existing concrete bridges," China Journal of Highway and Transport, vol. 25, no. 6, pp. 101-107, 2012.

[7] GB50010, Code for Design of Concrete Structures, China Construction Industry Press, Beijing, China, 2010.

[8] A. E. Naaman and M. Founas, "Partially prestressed beams under random-amplitude fatigue loading," Journal of Structural Engineering, vol. 117, no. 12, pp. 3742-3761, 1991.

[9] Z. H. Lu, Y. F. Ma, L. Song, and Z. W. Yu, "Experimental study on fatigue behavior of $8 \mathrm{~m}$ low-height reinforced concrete plate-girder of heavy-haul railway," Journal of Central South University (Science and Technology), vol. 48, no. 9, pp. 2550-2558, 2017.

[10] L. Z. Jiang, Z. Y. Wu, Z. H. Wu, and H. B. Zhu, "Experimental study on fatigue of reinforced concrete hollow beams,"
Journal of Railway Science and Engineering, vol. 7, no. 3, pp. 6-10, 2010.

[11] X. F. Feng, Y. P. Song, and M. C. Zhu, "An experimental study on the fatigue life of prestressed concrete beams under random-amplitude fatigue loading," China Civil Engineering Journal, vol. 39, no. 9, pp. 32-38, 2006.

[12] D.-I. Chang and W.-K. Chai, "A study on the fatigue strength behavior of reinforced concrete structures," International Journal of Pressure Vessels and Piping, vol. 40, no. 1, pp. 51-75, 1989.

[13] X. F. Li, P. G. Wu, and G. Y. Zhao, "Experimental Research on Bending Fatigue Behavior of High-Strength Concrete Beams," China Civil Engineering Journal, vol. 30, no. 5, pp. 37-42, 1997.

[14] H. C. Wang, J. X. Gong, and Y. C. Song, "Experimental Study on Corrosion Fatigue of RC Beams," China Journal of Building Structures, vol. 25, no. 5, pp. 105-110, 2004.

[15] J. Yang, T. Zhang, and Q. Sun, "Experimental study on flexural fatigue properties of reinforced concrete beams after salt freezing," Advances in Materials Science and Engineering, vol. 2020, pp. 1-15, 2020.

[16] Z. W. Yu, J. Z. Li, and L. Song, "Experimental study on fatigue behaviors of heavy-haul railway bridges," China Civil Engineering Journal, vol. 45, no. 12, pp. 115-126, 2012.

[17] K. Li, X. L. Wang, S. Y. Cao et al., "Fatigue Behavior of Concrete Beams Reinforced with HRBF500 Steel Bars," Structural Engineering and Mechanics, vol. 53, no. 2, pp. 311-324, 2015.

[18] J. Aidoo, K. A. Harries, and M. F. Petrou, "Fatigue behavior of carbon fiber reinforced polymer-strengthened reinforced concrete bridge girders," Journal of Composites for Construction, vol. 8, no. 6, pp. 501-509, 2004.

[19] J. Nie, Y. Wang, and C. S. Cai, "Experimental research on fatigue behavior of RC beams strengthened with steel plateconcrete composite technique," Journal of Structural Engineering, vol. 137, no. 7, pp. 772-781, 2011.

[20] C. Q. Wang, Y. G. Shen, R. F. Yang et al., "Experimental study on failure mechanism of prestressed concrete T girder," Journal of Railway Science and Engineering, vol. 14, no. 11, pp. 2369-2376, 2017.

[21] C. S. Wang, W. Z. Chen, and A. R. Chen, "System fatigue reliability assessment of riveted steel bridges," China Journal of Highway and Transport, vol. 21, no. 5, pp. 45-49, 2008.

[22] J. M. Hanson, Design for Fatigue, Handbook of Structural Concrete, Piterman Publishing INC, London, 1983.

[23] Z. B. Zeng and Z. R. Li, "Research on fatigue S-N curve of reinforcing bars in common reinforced concrete beams," China Civil Engineering Journal, vol. 32, no. 5, pp. 10-14, 1999.

[24] A. K. Pandey and M. Biswas, "Experimental verification of flexibility difference method for locating damage in structures," Journal of Sound and Vibration, vol. 184, no. 2, pp. 311-328, 1995.

[25] D. B. Li, Q. H. Lu, and Q. Qin, "Curvature modal analysis for bending structures," Journal of Qinghua University(science and Technology), vol. 42, no. 2, pp. 224-227, 2002.

[26] Y. Zhou, W. J. Yi, Y. Z. Jiang et al., "Practice of bridge modal flexibility identification using multiple-reference impact test," China Journal of Highway and Transport, vol. 28, no. 9, pp. 46-56, 2015. 